\title{
Theoretical investigation of the time-dependent behaviour of rockfill
}

\author{
L. A. OLDECOP* and E. E. $\operatorname{ALONSO}^{\dagger}$
}

\begin{abstract}
Long-term strain records obtained in large-diameter oedometer tests on compacted gravels demonstrated that strains could be linearly related with the logarithm of time. Delayed compressibility coefficients were found proportional to the conventional stress-induced compressibility coefficients. A framework rooted on the phenomenon of crack propagation in rock particles induced by stress corrosion mechanisms is adopted to explain macroscopic observations. A model of crack propagation in loaded disc-shaped particles has been developed in order to explain the nature of particle breakage and its relationship with time, macroscopic stress and total suction. Experimental observations such as the existence of threshold stresses that mark the onset of delayed deformations are explained by the model. It was also found that the main features of the delayed deformation of rockfill could be physically explained within the developed framework. In particular, a simple closed-form relationship between the coefficient of delayed deformation, the compressibility coefficient and a parameter describing the rate of crack propagation could be found. It was found to be consistent with experimental observations.
\end{abstract}

KEYWORDS: creep; gravels; particle crushing/crushability; suction; time dependence
Grâce aux enregistrements long-termes des contraintes obtenus dans des essais à l'oedomètre de large diamètre sur des graviers compactés, on a montré que les contraintes pouvaient être reliées au logarithme du temps de manière linéaire. On a aussi trouvé que les coefficients de compressibilité retardée étaient proportionnels aux coefficients de compressibilité conventionnelle (où la compressibilité est induite par une contrainte). Pour expliquer les observations macroscopiques, on a adopté un cadre basé sur le phénomène de propagation des fissures dans les particules rocheuses, induit par des mécanismes de corrosion sous contrainte. On a développé un modèle de propagation des fissures dans les particules discoïdes comprimées pour expliquer la nature de la rupture des particules et sa relation avec le temps, la contrainte macroscopique et l'aspiration totale. Le modèle explique les observations expérimentales telles que l'existence de contraintes de seuil marquant le début des déformations retardées. On a aussi trouvé qu'au sein du cadre développé on pouvait expliquer physiquement les caractéristiques principales de la déformation retardée de l'enrochement. En particulier, on a trouvé une relation de forme fermée simple entre le coefficient de déformation retardé, le coefficient de compressibilité et un paramètre décrivant le taux de propagation des fissures. Ce résultat correspondait à nos observations expérimentales.

\section{INTRODUCTION}

Rockfill shows a significant time-dependent behaviour. Continuous settlements have been recorded in rockfill dams after their construction, and for many decades (Sowers et al., 1965; Marsal, 1976; Sherard \& Cooke, 1987). The crest settlement records of some dams built during the twentieth century are shown in Fig. 1.

Dams are classified in four groups. Old concrete-faced rockfill dams (CFRD) made of dumped rockfill without compaction usually undergo large amounts of settlement, exceeding $1 \%$ of the height. In turn, modern CFRDs show a noticeable effect of compaction, and the magnitude of postconstruction settlements is reduced. The typical behaviour of central clay core dams with rockfill shells involves the occurrence of sudden settlement episodes during the first filling of the reservoir. This is related to the flooding of the rockfill in the upstream shell, a situation that is avoided in concrete-faced dams. This phenomenon is called 'collapse' deformation. Finally, dams with gravelly shells typically show very small post-construction settlements. This is attributed to the good gradation of the grain sizes and the

Manuscript received 23 December 2005; revised manuscript accepted 9 January 2007.

Discussion on this paper closes on 1 September 2007, for further details see p. ii.

Earthquake Engineering Institute (IDIA), Universidad Nacional de San Juan, Argentina.

$\dagger$ Department of Geotechnical Engineering and Geosciences, Universitat Politècnica de Catalunya, Barcelona, Spain. rounded shape of the gravel particles, preventing particle breakage and leading to a less compressible material.

The common factor in all these records is that the deformation process continues for many years. Data shown in Fig. 1 suggest that in most dams the deformation process is still active after 10,20 or 30 years of operation. In fact, most of the settlement records approach a linear logarithmic relationship between strain and time, and this would mean that the involved straining process is endless, although the rate of deformation continuously decreases with time.

Post-construction deformations of rockfill structures may be more or less relevant for their performance and safety, depending on the purpose of the structure and its nature. Post-construction settlements in rockfill dams usually do not pose a real threat for the structure or present problems for its operability. Pathological cases, such as the Ataturk Dam in Turkey (Cetin et al., 2000), which had lost almost all of its projected freeboard in the first five years after reservoir filling, are rare in dam engineering.

On the other hand, the operability and safety of railways impose tight limits for post-construction settlements of the supporting embankments (particularly those supporting highspeed railways). In any case, an understanding of the nature of the time-dependent deformations should be helpful in interpreting the behaviour of real rockfill structures and monitoring records. Time-dependent strains are commonly superposed on other sources of deformation driven by external actions, such as rainfall, flooding, repeated loading, and earthquakes. It is, indeed, by means of a thorough knowledge of the physical and chemical processes taking place within the structure that safety monitoring records can be interpreted, avoiding misleading conclusions. 


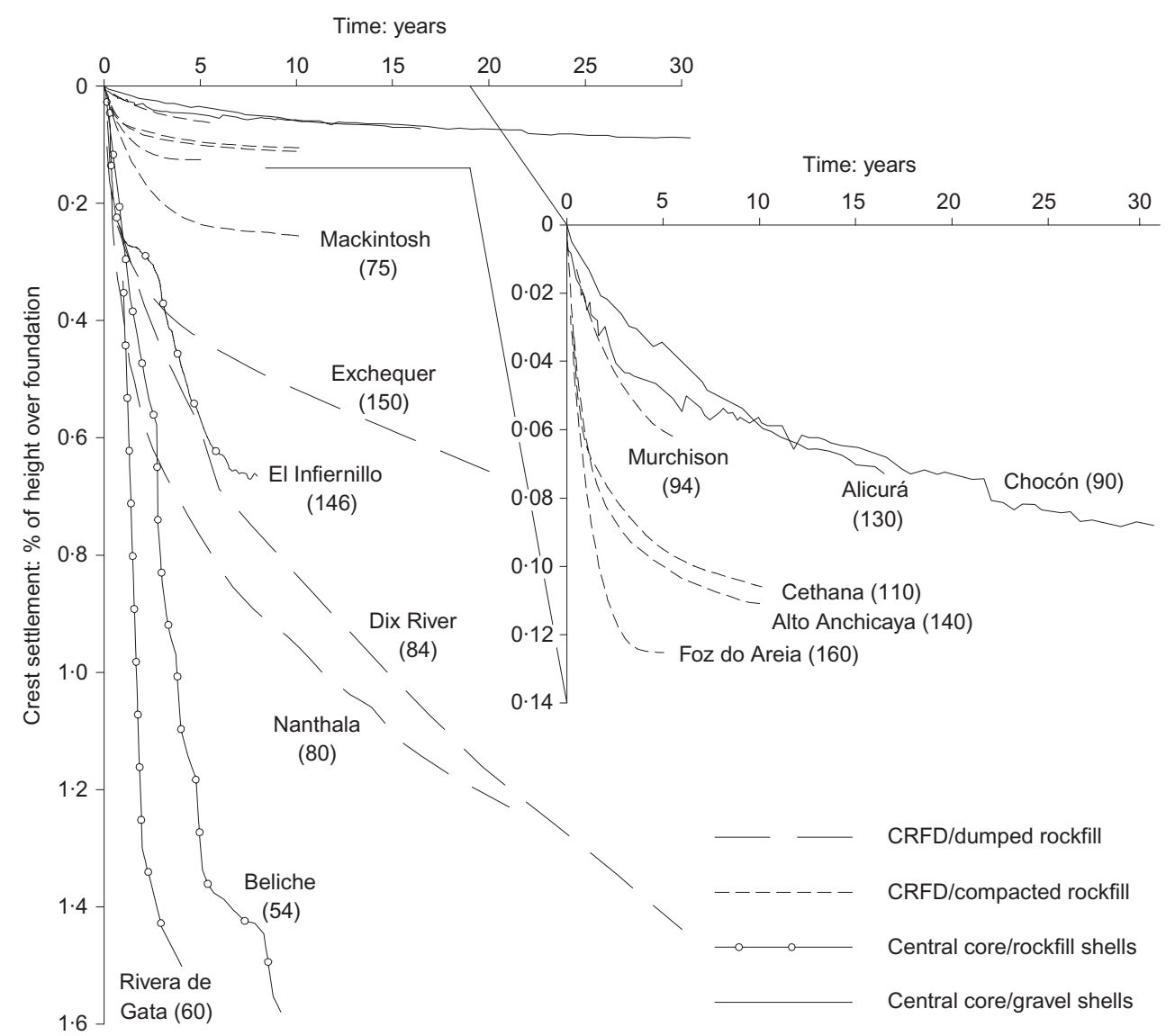

Fig. 1. Records of crest settlement of different types of rockfill dams built during the twentieth century. Name (height in m) of the dam next to each curve (Data sources: Marsal et al., 1976; Sherard \& Cooke, 1987; Soriano et al., 1992; Naylor et al., 1997)

Various constitutive models proposed in the past allow for the time-dependence of rockfill behaviour to be taken into account. Most of them use a logarithmic relationship between time and the long-term strain component (Sowers et al., 1965; Mesri \& Castro, 1987; Charles, 1991; Soriano \& Sánchez, 1999; Athanasiu et al., 2005). Other types of strain-time relationship have been proposed, such as the hyperbolic model of Charles (1989) and the viscoelastic approach of Justo \& Durand (2000). All these approaches are purely phenomenological, and hence they do not provide insight into the nature of the observed time-dependent behaviour of rockfill.

The present paper explores the fundamental phenomena that may be involved in the rockfill straining process, and develops a conceptual model able to explain the features of the observed behaviour. Some features of the time-dependent behaviour of gravel, as observed in large-diameter suctioncontrolled oedometer tests, are first discussed. They are interpreted within a general framework that associates delayed deformations with particle breakage. The propagation of a single crack in a rock particle is then analysed in some detail. A general expression for the time to breakage is derived. Then the behaviour of a disc-shaped brittle particle with a centred initial crack, subjected to two opposed concentrated loads, is analysed. Expressions relating the evolution of the crack length with time and with the overall macroscopic stress have been found. They provide an explanation for the delayed behaviour observed in rockfill structures. In the final section of the paper, a procedure is developed to find a closed-form expression for the timedependent strains generated at constant stress and constant relative humidity.

\section{EXPERIMENTAL OBSERVATIONS}

One-dimensional compression tests were carried out on specimens of a rockfill-type material, a crushed slate having a maximum particle size of $40 \mathrm{~mm}$. The relative humidity within the specimen was controlled by means of a vapour equilibrium technique, making it possible to gradually change the specimen water content and suction during the test (Oldecop \& Alonso, 2001, 2003). Tests were performed in load/suction control mode, following a prescribed path in the stress-suction space (Fig. 2(a)). The stress-strain behaviour obtained from those tests is shown in Fig. 2(b).

Time-dependent strain data were collected during the tests shown in Fig. 2. For each loading step or suction change, strain records under constant stress and suction were obtained. Fig. 3 shows the full set of records collected in test 4 , including stress-increment-induced strains and the strain record during the wetting path performed under constant stress. Similar time-strain data were collected for all tests and all loading steps. As no apparent steady state was attained in any strain record, strain data for the construction of stress-strain curves in Fig. 2(b) were conventionally selected at $1000 \mathrm{~min}$ after the instant of application of the corresponding stress increment. However, analogous stressstrain curves could have been built on the basis of vertical strain values measured at different time intervals. Fig. 4 shows the stress-strain experimental curves in normal compression, corresponding to time intervals of 10, 100 and $1000 \mathrm{~min}$ after the instant of application of each load increment (stress is plotted on a log scale). Therefore the compressibility index $\lambda$ is not only a function of stress $\sigma$ and total suction $\psi$, but also of the selected reference time $t^{\mathrm{r}}$ : 


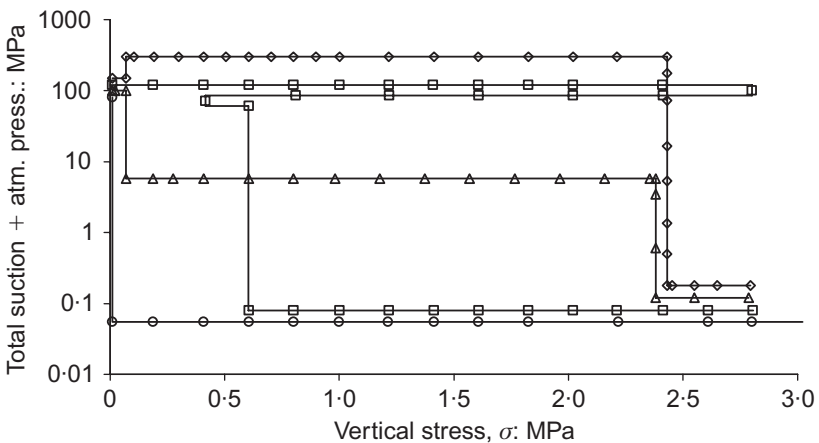

(a)

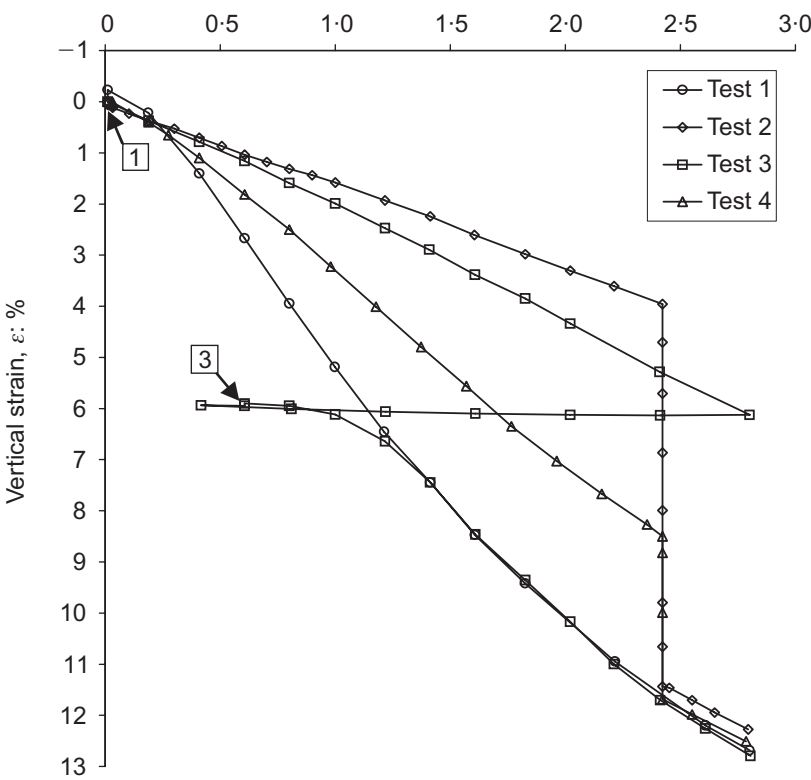

(b)

Fig. 2. One-dimensional compression tests with relative humidity control: (a) test paths in stress-suction space; (b) stressstrain curves with strain values measured at 1000 min after application of each load increment (Oldecop \& Alonso, 2003)

$$
\lambda\left(\sigma, \psi, t^{\mathrm{r}}\right)=\frac{\mathrm{d} \varepsilon_{\left(\psi, t^{\mathrm{r}}=\text { constant }\right)}}{\mathrm{d}(\ln \sigma)}
$$

Values of the compressibility index along the normal compression curves were derived from the datasets shown in Fig. 4. These values are plotted in Fig. 5 against the applied vertical stress. The derivative operation applied to the experimental data leads to the irregularities shown in the figure. However, if smooth curves are fitted to the experimental data in Fig. 4 the resulting compressibility curves show the regular shape also indicated in Fig. 5.

It is seen in Fig. 5 that, during the first stage, the compressibility index increases almost linearly with the applied stress, which means a linear stress-strain behaviour. In the second stage, the compressibility index tends to a constant value (that is, a linear strain-log stress normal compression line is approached). Analogous behaviour can be observed in the experimental data presented by Nakata et al. (2001), obtained from oedometer tests on three different natural sands with various formation void ratios. Moreover, the data in Fig. 5 show that the compressibility index also depends on total suction and, in a not so marked manner, on the reference time. It is also noted that, for increasing suction values, a narrower variation of the compressibility index with the reference time is obtained.

In the strain-time records of Fig. 3 it can be seen that, after a relatively short transient period (in most cases shorter

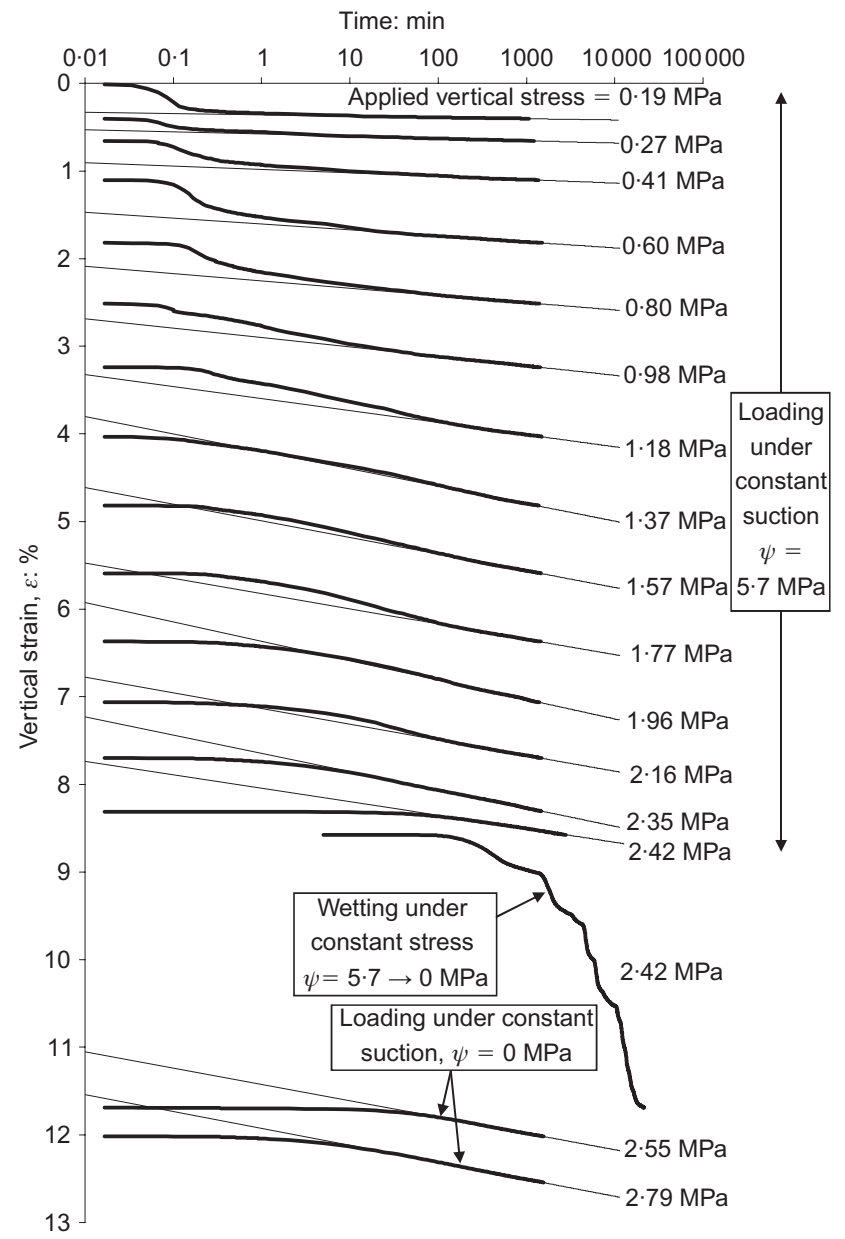

Fig. 3. Strain records obtained in each load step (under constant stress) of oedometer test 4

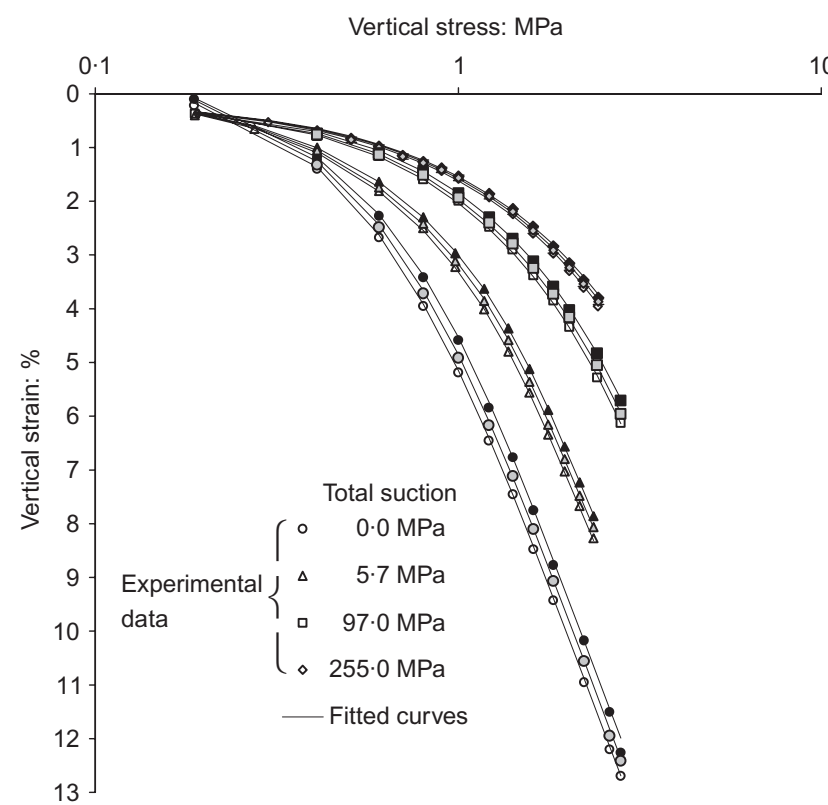

Fig. 4. Strain-stress curves measured at different time intervals after each load step application: black symbols, $t^{\mathrm{r}}=10 \mathrm{~min}$; grey symbols, $t^{r}=100 \mathrm{~min}$; open symbols, $t^{r}=1000 \mathrm{~min}$

than $10 \mathrm{~min}$ ), every strain record approaches a linear strain$\log$ time relationship. A logarithmic function was fitted to the long-term part $(t>100 \mathrm{~min})$ of these records. In this way, a time-dependent compressibility index was computed, 


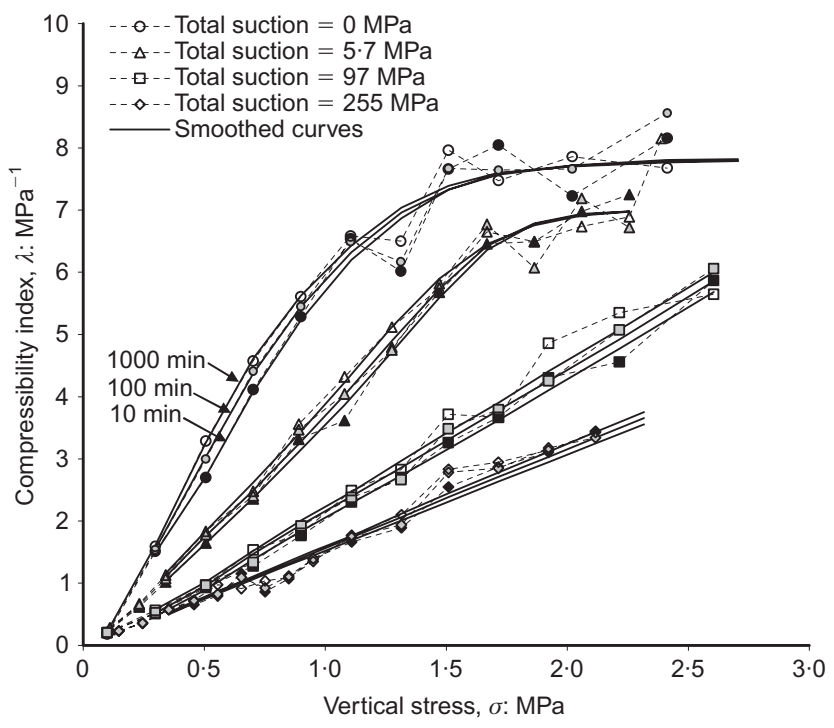

Fig. 5. Compressibility indices in normal compression, at constant suction, computed with strain values measured at different time intervals after load step application: black symbols, $t^{\mathrm{r}}=$ $10 \mathrm{~min}$; grey symbols, $t^{\mathrm{r}}=100 \mathrm{~min}$; open symbols, $t^{\mathrm{r}}=$ $1000 \mathrm{~min}$. Smooth curves derived from stress-strain curves fitted to experimental data presented in Fig. 4

which is formally identical to the secondary compressibility index usually adopted in modelling secondary soil consolidation:

$$
\lambda^{t}=\frac{\mathrm{d} \varepsilon}{\mathrm{d}(\ln t)}
$$

where $\mathrm{d} \varepsilon$ is the strain increment and $t$ is the time elapsed since the application of the last load increment. Values of $\lambda^{t}$ are plotted against the applied vertical stress in Fig. 6. Points corresponding to different total suction values are identified by means of different symbols. Although there is some scatter in the experimental data, the dependence of $\lambda^{t}$ on the applied stress and total suction can be readily observed for

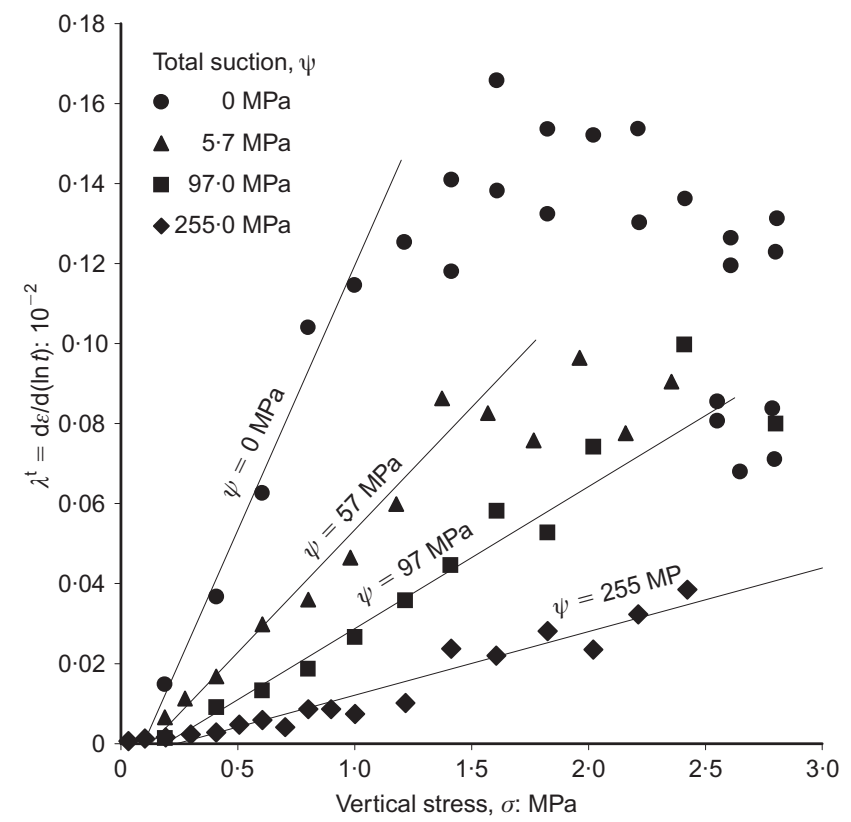

Fig. 6. Time-dependent compressibility index against applied stress for different constant suction values the initial stages of the experiments. Under higher stressstrain levels the behaviour is not so clear, and additional data under high confining stresses would be required to elucidate this point.

If the full set of measured $\lambda^{t}$ values is plotted against the compressibility index (taking $t^{\mathrm{r}}=1000 \mathrm{~min}$, for example), a relatively narrow correlation band is obtained (Fig. 7). This plot is similar to the correlation found by Mesri et al. (1990) between the secondary compression coefficient $C_{\alpha}$ and the compression index $C_{\mathrm{c}}$ for a variety of sandy soils tested in oedometer cells under a stress range of $0.05-$ $3 \mathrm{MPa}$. The limits of the correlation found by Mesri et al. (1990) are plotted in Fig. 7. They fall within a relatively narrow range $(0 \cdot 015-0 \cdot 1)$. In general, lower $\lambda^{t}$ values are found for the rockfill tested, and they are strongly dependent on the prevailing relative humidity. The data in Fig. 7, however, show that there is also a close relationship between $\lambda^{t}$ and $\lambda$ in rockfill materials. The reasons for this dependence will be explored later.

\section{MICROMECHANICAL CONCEPTUAL MODEL}

Oldecop \& Alonso (2001) proposed a micromechanical conceptual model to explain the features of rockfill compressibility. It hypothesises that, in the first stages of compression (isotropic or 1-D compression), rockfill deforms mainly because of particle rearrangement involving interparticle sliding and rotation. As compression proceeds, the void ratio decreases and the coordination number within the granular structure increases. At some point the granular structure becomes blocked, and no further strain increment can occur unless breakage of rock particles occurs. Such a hypothesis is supported by the substantial particle breakage usually observed in rockfill compression tests (Kjaernsli \& Sande, 1963; Sowers et al., 1965; Fumagalli, 1969; Marachi et al., 1969; Nobari \& Duncan, 1972; Marsal, 1973; Veiga Pinto, 1983).

In the proposed conceptual model, a rockfill element (Fig. $8(\mathrm{a})$ ), integrated by a certain number of rock particles containing cracks, is subjected to a compressive stress state (as given by an oedometer or isotropic compression test). Under the combined action of the applied stresses and water, cracks propagate at a certain velocity given by the rate of a

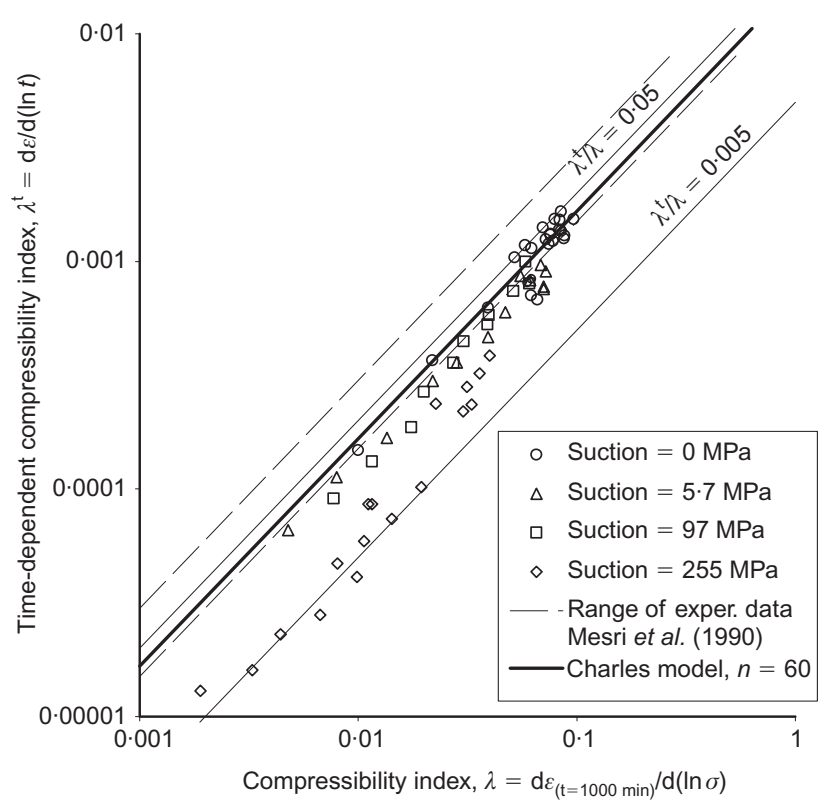

Fig. 7. Correlation between time-dependent compressibility index and compressibility index for tested rockfill 


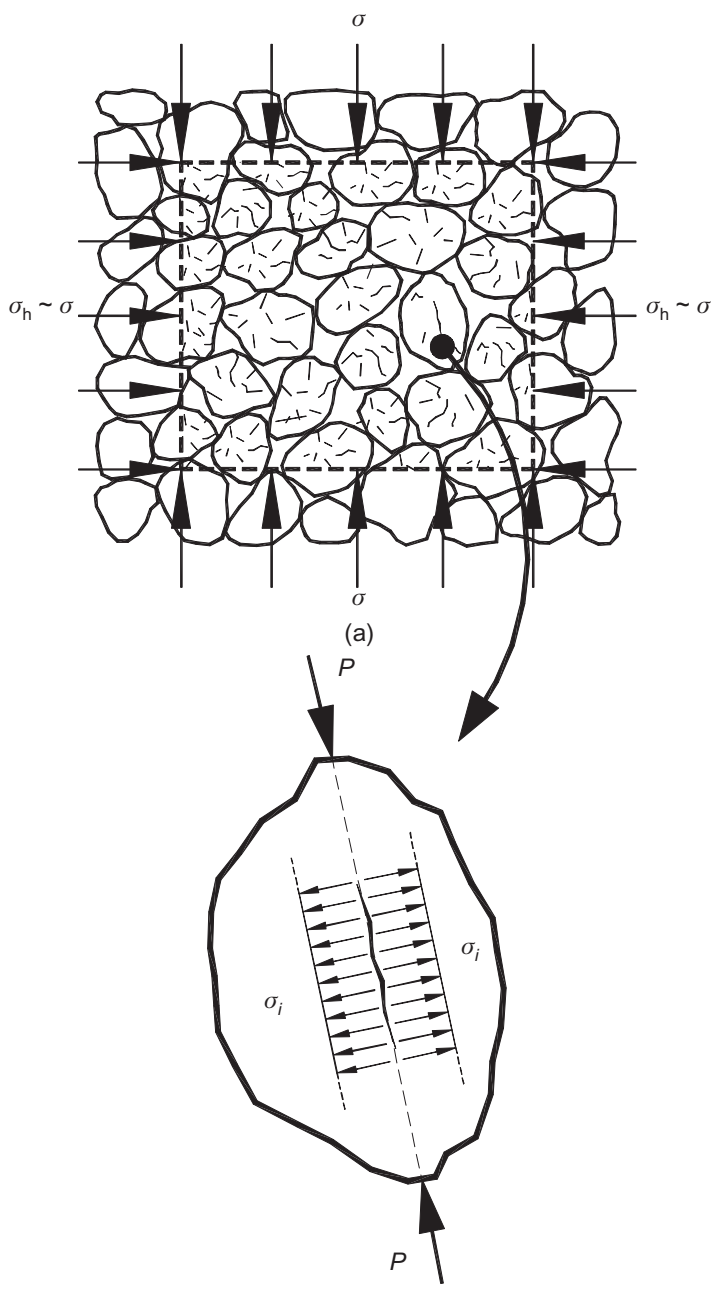

(b)

Fig. 8. (a) Rockfill element formed by rock particles containing macro- and microcracks and flaws; (b) rock particle subjected to contact loads

chemical reaction at the crack tip, known as stress corrosion (Wiederhorn et al., 1980; Freiman, 1984). Crack propagation eventually leads to the breakage of rock particles and to the consequent rearrangement of the granular structure in order to reach a new equilibrium configuration. Each of these rearrangements involves a macroscopic strain increment. Hence, upon blockage of the granular structure, the straining process of rockfill becomes controlled by the stress corrosion phenomenon. As stress corrosion causes the cracks to propagate at a finite velocity, and its value depends on the water energy, a dependence of rockfill deformations on time and relative humidity is expected.

In stress corrosion, the stress state at the crack tip enhances the corrosion reaction between the rock species and the water filling the crack. The stress state in the vicinity of the crack tip is characterised by the stress intensity factor, which in linear elastic fracture mechanics (Broek, 1986) is defined as

$$
K_{i}=\beta_{i} \sigma_{i}^{*} \sqrt{\pi a_{i}}
$$

where $a_{i}$ is the half-length of crack $i ; \beta_{i}$ is a non-dimensional factor that embodies the geometry of the particle, the position of the crack, the direction and point of application of loads, and the relative size of the crack in relation to the particle size; and $\sigma_{i}^{*}$ is the stress that would act across the plane of crack $i$ if the particle was not cracked (Fig. 8(b)).
The stress $\sigma_{i}^{*}$ in equation (3) will depend on the macroscopic stress $\sigma$ and on the current configuration of the granular structure. It would be expected that increasing the macroscopic stress $\sigma$ would also increase the local stress $\sigma_{i}^{*}$ on most of the cracks contained in the rockfill element. Therefore the stress intensity factor in most cracks would tend to increase with increasing applied load. This view is supported by the load chain mechanisms of stress transmission within granular materials (Cundall \& Strack, 1979). Particles located in a force transmission path will be essentially loaded by two large opposed forces (and other smaller stabilising forces). The idealised loading scheme of Fig. 8(b) is perhaps a reasonable hypothesis for a representative loaded rock particle within a granular aggregate.

The availability of water to produce the stress corrosion reaction is usually measured by means of the relative humidity in the air surrounding the specimen. Within a system in thermodynamic equilibrium, the relative humidity is biunivocally related to total suction $\psi$ by the psychrometric relationship (Coussy, 1995). Therefore total suction is also a suitable variable for measuring the action of water on crack propagation.

Data obtained from stress corrosion experiments are usually plotted as crack velocity $V$ against stress intensity factor $K$ under constant RH (or constant $\psi$ ). The typical shape of such stress corrosion curves is schematically shown in Fig. 9(a). Two singular values of $K$ can be identified. $K^{\mathrm{C}}$ is known as the fracture toughness, and with some limitations can be considered as a material property (Broek, 1986). As the stress intensity factor $K$ exceeds $K^{\mathrm{C}}$ the crack propagates in a catastrophic manner: that is, the piece containing the crack suddenly breaks off. $K^{0}$ is known as the stress corrosion limit. For values of $K$ smaller than $K^{0}$ the corrosion reaction arrests, and cracks do not propagate at all. Cracks falling in the interval $K^{0}<K<K^{\mathrm{C}}$ will propagate with a finite velocity $V$. Atkinson (1984) published an extensive compilation of stress corrosion experimental data for various minerals and rocks (Fig. 9(b)).

Charles (1958) proposed a simple expression for fitting stress corrosion experimental data, used here in a modified form, to make it dimensionally correct:

$$
V=V_{0}\left(\frac{K}{K^{\mathrm{C}}}\right)^{n}
$$

This equation has no physico-chemical fundamentals, found in later and more elaborated models (Wiederhorn et al., $1980,1982)$. It is a pure phenomenological model. $V_{0}$ and $n$ are the parameters of the Charles equation, usually obtained by fitting experimental data. It is usual practice in fracture mechanics to consider $V_{0}$ and $n$ as material properties. Equation (4) fits the experimental data well, at least in the socalled zone 1 of crack propagation (see Fig. 9(a)), and this is shown in Fig. 9(b), where a set of curves for various values of $n$ is plotted against experimental data collected in zone 1 of the crack velocity diagram. In zone 1 , crack propagation occurs as a result of the stress corrosion reaction referred to above. Other zones (2 and 3) are identified in some experimental datasets (Freiman, 1984). In zone 2 the propagation velocity becomes nearly constant, which suggests that the controlling mechanism is diffusion of the corrosive species (water vapour) along the crack length. In zone 3 water cannot reach the tip of the crack, because propagation occurs too rapidly, and hence the $V(K)$ curve does not display any dependence on the RH. Experimental data, such as those shown in Fig. 9(b), suggest that stress corrosion curves under different $\mathrm{RH}$ values are nearly parallel (Wiederhorn et al., 1980): that is, the parameter $n$ does not depend on the RH for a usual range of values (say $\mathrm{RH}$ 


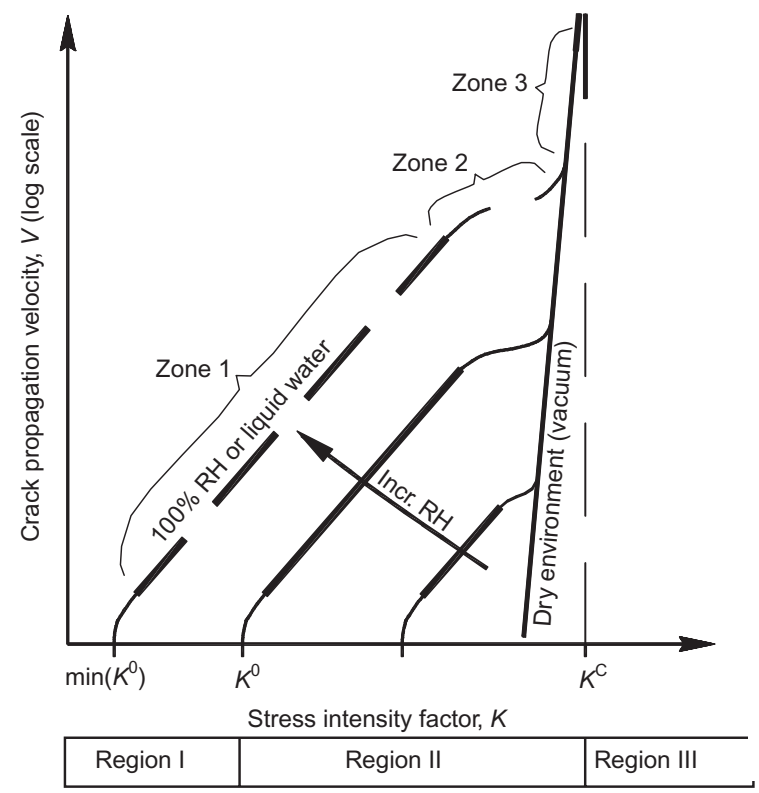

(a)

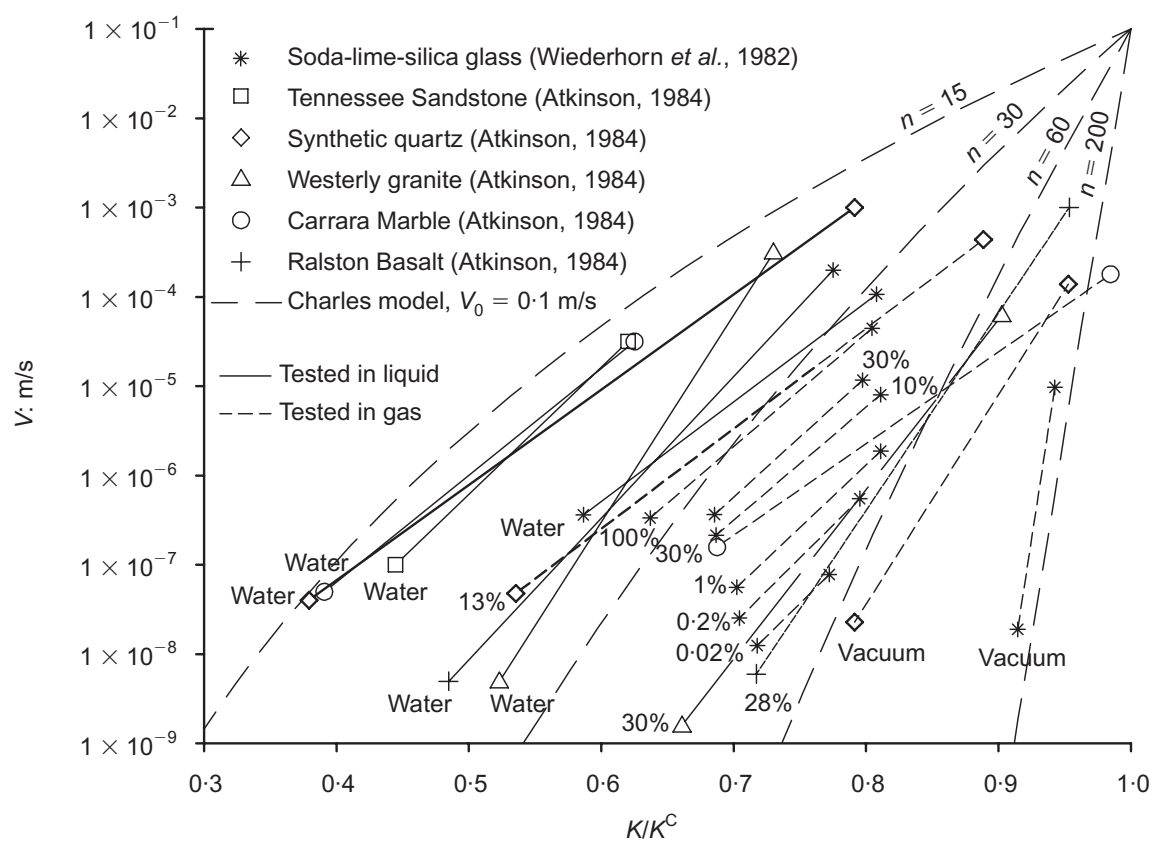

(b)

Fig. 9. (a) Schematic stress corrosion curves and conceptual model by Oldecop \& Alonso (2001); (b) stress corrosion experimental data from different rocks, quartz and glass, and plots of Charles model. Testing condition indicated next to each curve: immersed in liquid water, environment with controlled relative humidity (in \%) or vacuum

over 20\%). Moreover, experimental data presented by Freiman (1984) suggest that $V$ in zone 1 increases with the $\mathrm{RH}$ in an almost linear manner. $V_{0}$ in equation (4) therefore includes the effect of relative humidity or total suction.

A unique $K$ value could theoretically be assigned to all cracks existing in a given particle arrangement under stress, and therefore they will form an ordered series along the $K$ axis in Fig. 9(a). Every time a stress increment is applied, the series of cracks will move towards higher $K$ values. The reverse will occur upon unloading. All cracks falling within region III will immediately break after load application. Cracks in region II will propagate, $V$ being the initial velocity of propagation given by the stress corrosion curve. The time-dependent component of strain arises from the breakage of cracks lying in region II. Since, in region II, the velocity of crack propagation depends on the $\mathrm{RH}$, the timedependent strains of rockfill will also depend on the $\mathrm{RH}$, as observed in experiments.

\section{SUBCRITICAL PROPAGATION OF A SINGLE CRACK}

The propagation of a single crack contained in a rock particle will now be considered, assuming that the applied stress state and the prevailing $\mathrm{RH}$ remain constant. It will also be assumed that no significant changes occur in the configuration of the particle assembly during propagation of crack $i$, so that $\sigma_{i}^{*}$ in equation (3) can also be taken as a constant. 
Replacing equation (3) in equation (4), the following expression for the propagation velocity of crack $i$ as a function of crack length is obtained.

$$
V_{i}=\frac{\mathrm{d} a_{i}}{\mathrm{~d} t}=A_{i} a_{i}^{n / 2}
$$

where $A_{i}=V_{0}\left(\beta_{i} \sigma_{i}^{*} \sqrt{\pi} / K^{\mathrm{C}}\right)^{n}$. As will be shown later, it is reasonable to assume that the factor $\beta_{i}$ remains nearly constant during most of the propagation time of crack $i$. Only when the breakage of the particle is approached does $\beta_{i}$ increase rapidly. Hence $A_{i}$ also remains nearly constant. Inverting equation (5) and integrating, the following relationship between time and crack length is obtained (see Appendix).

$$
t=\frac{1}{A_{i}} \frac{2}{n-2}\left(a_{0 i}^{-((n / 2)-1)}-a_{i}^{-((n / 2)-1)}\right)
$$

where $a_{0 i}$ is the initial crack half-length, that is, the crack length at the time of load application. The crack half-length $a_{i}$ increases during crack growth. As common values of $n$, obtained from experiments, are large (between 15 and 200: see Fig. 9(b)), as the breakage of the crack $i$ is approached, the second term within the parentheses becomes negligible if compared with the first term, and $t \rightarrow t_{i}^{\mathrm{b}}$, where $t_{i}^{\mathrm{b}}$ is the time elapsed between the instant of load application and the breakage of the considered crack. Hence

$$
t_{i}^{\mathrm{b}}=\frac{1}{A_{i}} \frac{2}{n-2} a_{0 i}^{-((n / 2)-1)}=\frac{2}{n-2} \frac{a_{0 i}}{V_{0 i}}
$$

where

$$
V_{0 i}=V_{0}\left(\beta_{i} \sigma_{i} \sqrt{\pi a_{0 i}} / K^{\mathrm{C}}\right)^{n}
$$

is the propagation velocity of a crack of half-length $a_{0 i}$.

Equation (7) states that a one-to-one relationship exists between the time to breakage for a single crack and its initial length. It could be a surprising fact that, as seems to follow from equation (7), the time to breakage does not depend on the size of the body containing the crack (that is, the rock particle). In other words, equation (7) does not account for the length of the path to be followed by the crack until the edges of the rock particle are reached. In order to investigate this result, and to gain some insight into the features of the propagation process for a small crack contained in a particle, the following example was developed.

\section{A SIMPLE PARTICLE MODEL}

Consider a disc of diameter $D$ and thickness $B$, made of a perfectly elastic-brittle material, containing a central crack going through the thickness of the disc (Fig. 10). The disc is loaded by two concentrated forces $P$, diametrically opposed. The crack is oriented in the same loading direction, and it has a length of $2 a_{i}$. The stress intensity factor characterising the stress state at the crack tips is given by equation (3), where $\beta_{i}$ is approximated by (Tada et al., 1985)

$$
\begin{aligned}
\beta_{i}= & \frac{1}{1-\alpha}\left(1-0.4964 \alpha+1 \cdot 5582 \alpha^{2}-3 \cdot 1818 \alpha^{3}\right. \\
& \left.+10 \cdot 0962 \alpha^{4}-20 \cdot 7782 \alpha^{5}+20 \cdot 1342 \alpha^{6}-7 \cdot 5067 \alpha^{7}\right)
\end{aligned}
$$

where $\alpha=2 a_{i} / D$. The stress $\sigma_{i}^{*}$, across the crack plane, can be computed from (ISRM, 1978)

$$
\sigma_{i}^{*}=\frac{0 \cdot 636 P}{D B}
$$

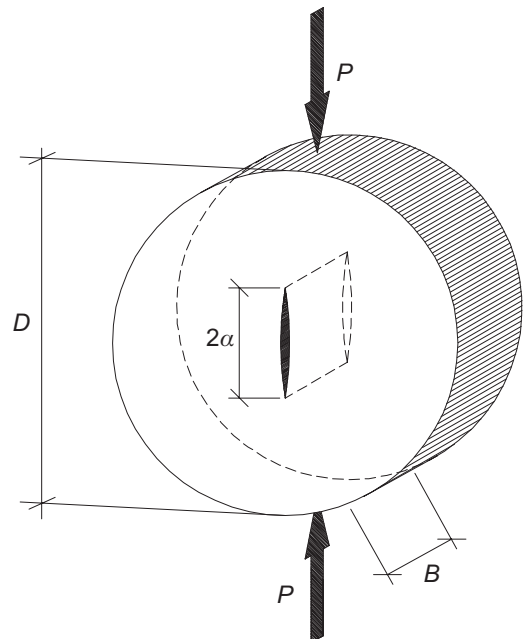

Fig. 10. Disc model for rock particle having central crack of length $2 a_{i}$

The vertical 'macroscopic' stress equivalent to the concentrated load $P$ is given by

$$
\sigma=\frac{P}{D B}=\frac{\sigma_{i}^{*}}{0 \cdot 636}
$$

Using this simple model, the propagation of cracks of different initial lengths can be analysed. Given a disc diameter $D$, the applied stress $\sigma$, and the initial value for the crack length $a_{i}(t=0)$, the corresponding instant values of $\beta, K$ and $V$ can be computed from equations (9), (3) and (4) respectively. Carrying out numerically the integration of

$$
\mathrm{d} a_{i}=V\left(K_{i}\right) \mathrm{d} t
$$

the evolution of the crack length in time can be obtained. Fig. 11(a) shows the results obtained with such a model, for a disc $40 \mathrm{~mm}$ in diameter, loaded with $\sigma^{*}=5 \mathrm{MPa}(P=$ $2 \mathrm{kN}, \sigma=7.87 \mathrm{MPa}$ ) and initial crack half-lengths $a_{0 i}=4$,
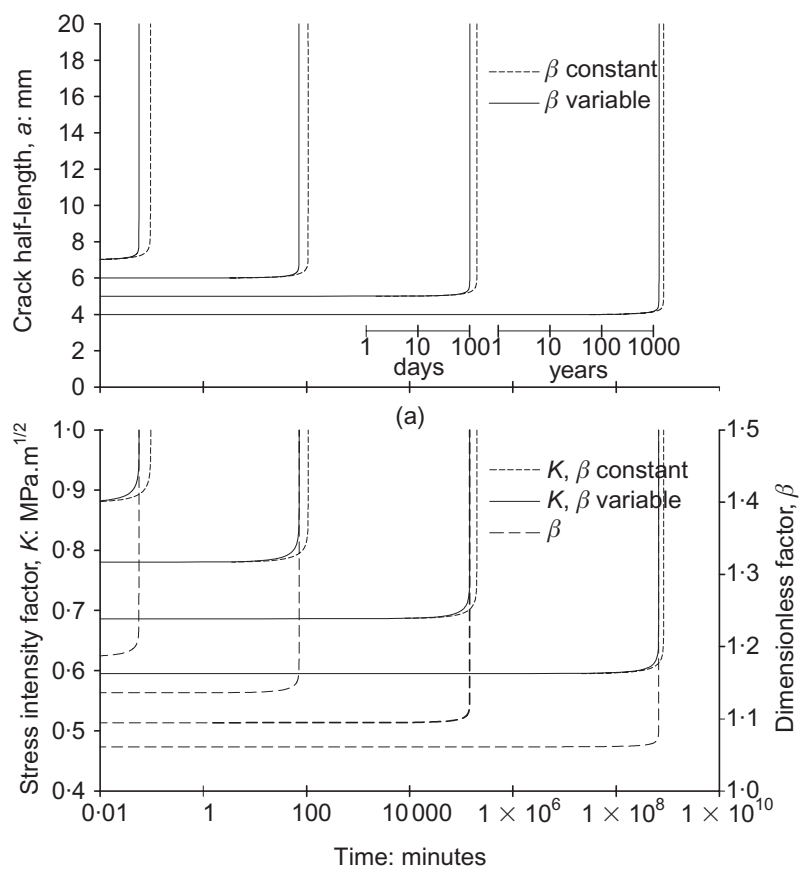

(b)

Fig. 11. Disc model with $\sigma^{*}=5 \mathrm{MPa}$, results for different initial crack lengths $=4,5,6$ and $7 \mathrm{~mm}$ : (a) evolution of crack length; (b) evolution of stress intensity factor and $\beta$ 
5,6 and $7 \mathrm{~mm}$. Values for the parameters of the Charles law $V_{0}=0 \cdot 1 \mathrm{~m} / \mathrm{s}, n=60$, were chosen, being well within the range of the experimental data shown in Fig. 9(b). A fracture toughness $K^{\mathrm{C}}=1 \mathrm{MPa}^{0.5}$ was selected from values reported in the literature for sedimentary rocks (Atkinson, 1984).

The selected 'macroscopic' stress, $\sigma=7.87 \mathrm{MPa}$, in the previous example is somewhat higher than the stress range applied in the rockfill tests presented in Figs 2 and 4. This is justified by taking into account the unequal distribution of contact forces within a granular structure due to the stress transmission by particle chains (Cundall \& Strack, 1979). Particles pertaining to such load chains may bear forces (and stresses) significantly larger than the mean stress, applied on the specimen boundaries. Nakata et al. (2001) compared the so-called 'yield stress' of sands compressed up to high stress levels in oedometer tests with the crushing strength of individual particles compressed between two parallel platens. Nakata et al.'s yield stress is defined by the point of bending of the virgin compression curve in an oedometer test, when plotted with the stress axis in logarithmic scale and the strain axis in natural scale. Although in the experimental data presented in Fig. 4 such bending occurs for a wide range of stress, the yield stress can be conventionally computed as the intersection of two tangent lines fitted to the initial and final parts of the virgin compression curve. The test results obtained by Nakata et al. show that the crushing strength of individual particles are between 2 and 15 times the yield strength, for five sands with different particle sizes and different initial void ratios. On the basis of these observations, it seems likely that the stress level selected for the disc model is representative of the actual stresses carried by the rockfill particles within the oedometer tests presented in Figs 2 and 4.

The propagation process (Fig. 11) occurs in two stages. During the first stage, when the crack length is small compared with the particle diameter, the crack propagates slowly and at a nearly constant rate. In the second stage the propagation velocity suddenly increases, leading to crack breakage in a very short period (always bearing in mind that the timescale is logarithmic in Fig. 11). Moreover, the factor $\beta$ remains nearly constant for most of the propagation process, that is, during the slow stage (Fig. 11(b)) (except for large cracks, having very short life). This was the main assumption made in order to derive equation (11). Assuming that $\beta$ is constant during the whole breakage process leads to an overestimation of the time to breakage $t_{i}^{\mathrm{b}}$, as can also be seen in Fig. 11(a). In the whole range of times in Fig. 11 , and certainly covering all periods of time of interest in civil engineering works, overestimation of the time to breakage made by applying equation (7) ranges from 68\% (for the $7 \mathrm{~mm}$ initial half-length crack) to $24 \%$ (for the $4 \mathrm{~mm}$ initial half-length crack). This means that the true time to breakage can be obtained from equation (7) by applying a correction factor $\eta=0 \cdot 6-0 \cdot 81$. For the sake of rigour this correction factor will be included in the following derivations, although it will be soon demonstrated that, given its range of values, it has no practical consequences in the general formulation of the proposed model.

The evolution of crack propagation shown in Fig. 11 explains why the time to breakage is essentially independent of the distance between the crack tip and the edges of the rock particle, as explained by equation (7). In fact, once the rate of crack propagation increases rapidly, the actual dimensions of the rock body are irrelevant in controlling the time to breakage. The time to breakage is essentially controlled by the initial size of the crack (for a given tensile stress acting on the plane of the crack). It is also interesting to note in Fig. 11 that a very wide range of values of time to breakage is obtained under a constant applied stress for a relatively narrow range of initial crack lengths.

These results may be interpreted in a different manner. For a given applied stress, the survival time of a crack with a given initial size $\left(2 a_{0 i}\right)$ may be computed as indicated above. All crack lengths having a given survival time may then be plotted against the confining stress. This type of plot is shown in Fig. 12(a) for survival times of $1 \mathrm{~min}, 1000 \mathrm{~min}$, $1 \mathrm{yr}$ and $1000 \mathrm{yrs}$. For time intervals of interest in practice (say, from $1 \mathrm{~min}$ to $1000 \mathrm{yrs}$ ), the range of crack lengths found for a giving confining stress provides an estimation of the active or significant initial crack sizes for a particular rockfill material. The size of significant cracks increases as the confining stress decreases. But there is obviously one limit: the size of the rock particle. As the applied stress decreases, the active range of effective crack lengths decreases, and its value becomes closer and closer to the particle size. The proximity of the particle edges makes the crack propagate faster than it would for the same crack embedded in an infinite body. This size effect on crack behaviour is introduced in the model by the factor $\beta$. An opposite effect derives from the fact that the uniform distribution of tensile stress across the plane of the crack (as assumed in the disc model) holds only for the central third of the disc diameter. Cracks with lengths that exceed this central zone are subjected to lower stress levels than smaller cracks (under the same load). This means that the survival

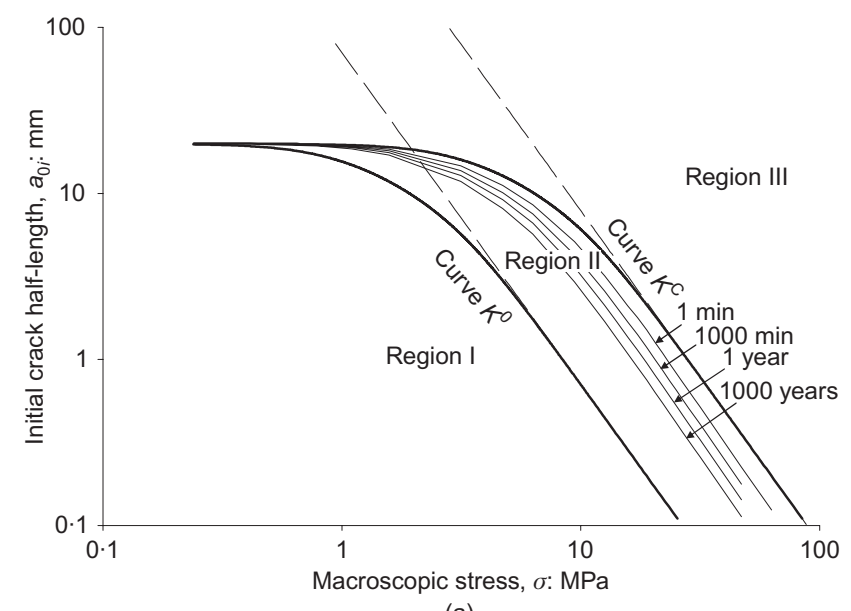

(a)

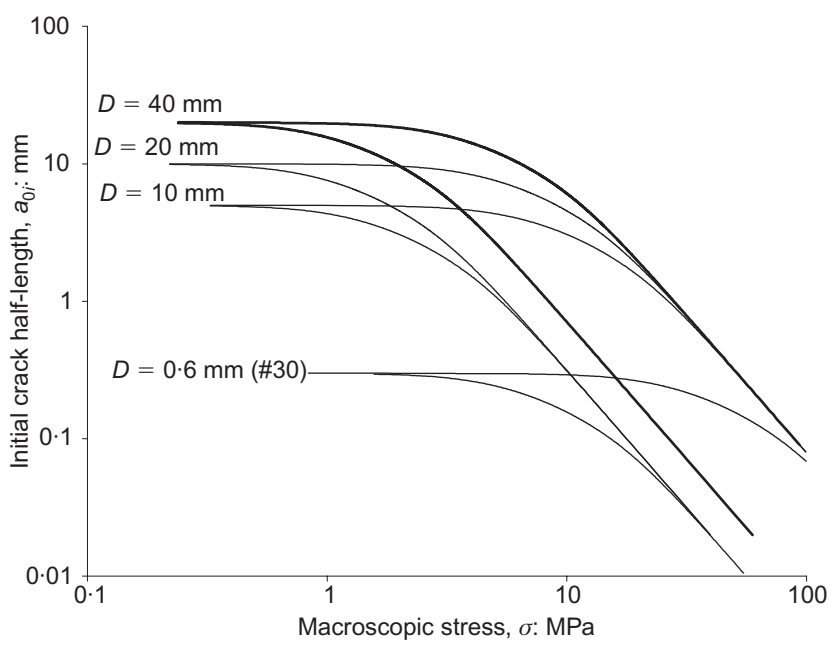

(b)

Fig. 12. Disc model: (a) relationship between crack length, applied macroscopic stress and survival time, disc diameter $40 \mathrm{~mm}$; (b) active ranges of crack sizes for several particle diameters ranging from $0.6 \mathrm{~mm}$ to $40 \mathrm{~mm}$ 
time of large cracks (larger than one third of the particle diameter) would be somewhat longer than predicted by the model proposed here. Hence points pertaining to the curved part of the isochrones shown in Fig. 12 would lie somewhat to the right of the plotted curves. However, this effect does not invalidate the reasoning and conclusions regarding the model results presented in Fig. 12.

On the other hand, the time to breakage for cracks within the active range (say with $a_{0 i}=1$ to $8 \mathrm{~mm}$ in the example solved) may range from zero (instantaneous breakage) to millions of years. This singular feature can be intuitively related with the observed fact that most rockfill dams display an apparently indefinite process of settlement accumulation in time.

Two other curves have been plotted in Fig. 12(a). The $K^{\mathrm{C}}$ curve is given by the $(a, \sigma)$ values defining a stress intensity factor (equation (3)) equal to $K^{\mathrm{C}}$ (assuming $K^{\mathrm{C}}=$ $1 \mathrm{MPa} \cdot \mathrm{m}^{1 / 2}$ ). The $K^{0}$ curve corresponds to a stress intensity factor equal to the stress corrosion limit $K^{0}$. The stress corrosion limit is assumed to be $K^{0}=0 \cdot 3 K^{\mathrm{C}}$ on the basis of theoretical considerations by Atkinson \& Meredith (1987).

Three regions, which have the same meaning as in Fig. 9(a), are defined by the curves plotted in Fig. 12(a). Region II, between the $K^{0}$ and $K^{\mathrm{C}}$ curves, defines, for a given applied stress, the active range of crack lengths, that is, the cracks currently being propagated. The limits of region II can be more precisely established as the region limited by two limiting times (small and very large) to reach the crack failure. As mentioned before, region II of active cracks tends to vanish as the confining stress decreases. This means that, under low stresses, region II may not exist: that is, rockfill may display a time-independent behaviour. This is indeed the behaviour observed in load-controlled oedometer tests carried out by Oldecop \& Alonso (2001). They defined a 'threshold stress' that marks the onset of time-dependent and water-dependent behaviour. For stress states below such a threshold, no particle breakage was detected, as follows from Fig. 12(a), and hence all the measured strain was induced by particle rearrangement.

If the active range is computed for different 'particle sizes' (that is, disc diameters), it can be shown that the threshold stress increases as the particle size decreases (Fig. 12(b)). This means that the straining process of rockfill is affected by a size effect. This is also an experimental fact. It is well known that the breakage of rockfill occurs readily under relatively low stress levels. On the other hand, sands must be compressed under very high stresses in order to induce particle breakage (Yamamuro \& Lade, 1996).

\section{RELATIONSHIP BETWEEN TIME TO BREAKAGE AND STRESS INTENSITY FACTOR}

From equations (3), (7) and (8) the following relationship can be derived between the initial stress intensity factor $K_{0 i}$, which characterises crack $i$ at $t=0$, and the time to breakage of the same crack.

$$
K_{0 i}=\left[\frac{2 a_{0 i}}{(n-2) V_{0} \eta t_{i}^{\mathrm{b}}}\right]^{1 / n} K^{\mathrm{C}}
$$

If the simple disc model is assumed to be representative of the general nature of particle breakage phenomena occurring within the rockfill granular structure, Fig. 12(a) indicates that, for a given applied stress, the possible variation of the crack length $a_{0 i}$ within the active range (region II) is relatively narrow. Moreover, $a_{0 i}$ in equation (13) is affected by a very small exponent $(=1 / n, n$ being in the range $15-$ 200: see Fig. 9(b)). Therefore, if a single reference length $a_{0}$ is defined for an arbitrary time to breakage, $t_{i}^{\mathrm{b}}=1000 \mathrm{~min}$, it can be shown that the active crack sizes in Fig. 12(a) fulfil the following condition along the whole range of stresses displayed.

$$
\begin{aligned}
& \left(\frac{a_{0 i}}{a_{0}}\right)^{1 / n}=0.992-1.004 \text { for } a_{0}=a\left(t_{i}^{\mathrm{b}}=1000 \mathrm{~min}\right), \\
& a_{0 i}=a\left(t_{i}^{\mathrm{b}}=1 \mathrm{~min} \text { to } 1000 \text { years }\right), \text { with } n=60
\end{aligned}
$$

Therefore the $a_{0 i}$ value in equation (13) may substituted with a small error by a single reference crack size $a_{0}$. In addition, owing to the small values of the exponent $1 / n$, the actual influence of the correction factor $\eta(=0 \cdot 6-0 \cdot 81)$ in equation (13) can be neglected. Hence equation (13) becomes

$$
K \cong\left[\frac{2 a_{0}}{(n-2) V_{0} t}\right]^{1 / n} K^{\mathrm{C}}
$$

In this relationship $t$ is the time elapsed since the start of the applied load and the failure of the considered crack, and $K$ is the initial stress intensity factor for that crack. As $a_{0}$, $V_{0}, n$ and $K^{\mathrm{C}}$ are constants, the time to breakage of a crack and its initial stress intensity factor are related by a unique relationship.

As a result, a new interpretation can be given to Fig. 9(a). The plot can be seen as the relationship between the initial velocity of propagation of each crack contained in the rockfill element, at the instant when such conditions of stress and suction are just applied, and the initial stress intensity factor at the same crack under the newly applied conditions. As the time to breakage is univocally related to the initial velocity of propagation, it can be stated that, once a certain time $t^{\mathrm{r}}$ has elapsed since the application of the current load conditions, all cracks that had an initial stress intensity factor larger than $K^{\mathrm{r}}$, given by equation (14), are now already broken. The 'crack $r$ ' itself is at impending breakage, and the rest of the cracks are either still propagating (in region II) or not propagating (region I). This interpretation leads to a model for the development of strains in time, described in the following section.

\section{A MODEL FOR THE DEVELOPMENT OF TIME- DEPENDENT STRAIN UNDER CONSTANT STRESS AND SUCTION}

At a given stage of deformation, the granular assembly forming the rockfill element of Fig. 8(a) can be viewed as a unique body with a particular geometry. Then the tensile stress $\sigma_{i}$ within a stressed particle will be proportional to the applied macroscopic stress:

$$
\sigma_{i}^{*}=\chi_{i} \sigma
$$

where $\sigma$ is the applied (controlled) macroscopic stress, and $\chi_{i}$ is a proportionality constant. Replacing equation (15) in equation (3),

$$
K_{i}=\beta_{i}^{*} \sigma \sqrt{\pi a_{i}} \text { with } \beta_{i}^{*}=\chi_{i} \beta_{i}
$$

Of course, the factor $\chi_{i}$ will vary (and therefore also $\beta_{i}^{*}$ ) with the configuration of the particle assembly, and hence it will change each time a particle breaks and a rearrangement of the granular structure occurs. However, as creep strain increments during a single load step are relatively small, it seems reasonable to assume that the propagation and breakage of each crack occurs with no interaction with other cracks in the rockfill assembly. This means that the propagation and breakage of crack $i$ will not have any effect on the factors $\chi_{i}$ and $\beta^{*}$ for the rest of the cracks. 
The basic idea underlying the proposed model is that each breaking episode of a crack within the rockfill specimen is associated with a unique value of permanent macroscopic strain. Consider the rockfill element of Fig. 8(a) being at the stress-strain point $\left(\sigma_{0}, \varepsilon_{0}\right)$ belonging to a normal compression line such as those presented in Fig. 2. Stress and suction remain constant. The normal compression lines in Fig. 2 correspond to a conventional reference time $t^{\mathrm{r}}=$ $1000 \mathrm{~min}$, elapsed between the instant of application of current loads (stress and suction) and the measurement of strain. If an additional lapse of time $\Delta t$ is allowed for the specimen under the same stress state, an additional increment of strain $\Delta \varepsilon$ will develop, as follows from the experimental data presented in Figs 3 and 4. Fig. 13(a) illustrates the process schematically.

The value of the strain increment $\Delta \varepsilon$ can be related to the time increment $\Delta t$. During $\Delta t$, all cracks lying between $K^{\mathrm{r}}$ and $K^{\mathrm{r}}-\Delta K$ will break (Fig. 13(b)). The breakage of these cracks is assumed to lead the macroscopic strain increment $\Delta \varepsilon$. The stress intensity factors of the first non-broken cracks at $t^{\mathrm{r}}$ and $t=t^{\mathrm{r}}+\Delta t$ are given by equation (14), and hence $\Delta K$ can be expressed as

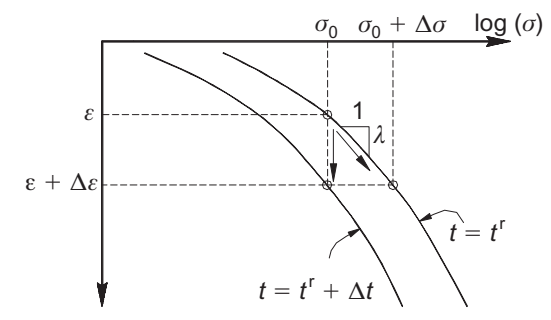

(a)

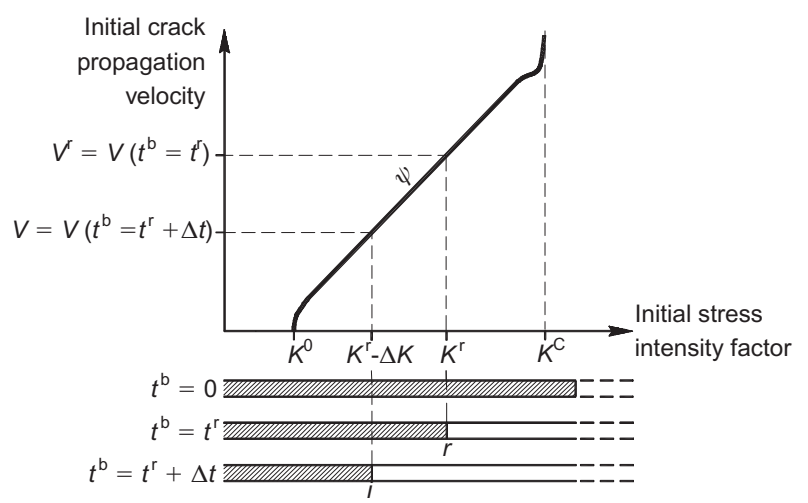

(b)

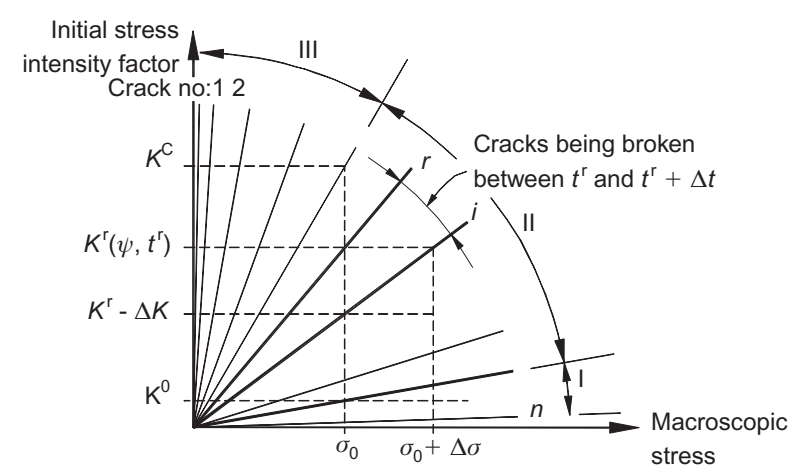

(c)

Fig. 13. Time-dependent conceptual model for rockfill in compression

$$
\begin{aligned}
\Delta K & =K^{\mathrm{r}}-K(t) \\
& \cong\left[\frac{2 a_{0}}{(n-2) V_{0}}\right]^{1 / n}\left[\left(\frac{1}{t^{\mathrm{r}}}\right)^{1 / n}-\left(\frac{1}{t}\right)^{1 / n}\right] K^{\mathrm{C}}
\end{aligned}
$$

Looking at the scheme in Fig. 13(a), it is clear that the same final strain value $\varepsilon=\varepsilon_{0}+\Delta \varepsilon$ can be obtained at the reference time $t^{\mathrm{r}}=1000 \mathrm{~min}$ by increasing the applied stress in some suitable amount $\Delta \sigma$. Such $\Delta \sigma$ should cause the crack, initially at $K^{\mathrm{r}}-\Delta K$ under stress $\sigma_{i}$, to be moved to $K^{\mathrm{r}}$ (Fig. 13(b)). This would imply breakage of all the cracks lying between $K^{\mathrm{r}}-\Delta K$ and $K^{\mathrm{r}}$. This is indeed the set of cracks associated with $\Delta \varepsilon$, but now owing to the application of $\Delta \sigma$, they break at time $t^{\mathrm{r}}$ instead of time $t^{\mathrm{r}}+$ $\Delta t$.

The relationship between the macroscopic stress $\sigma$ and the stress intensity factor $K_{i}$ in any single crack $i$ is given by equation (16). Assuming again that, in the range of interest of crack sizes, the factor $\beta_{i}$ remains nearly constant, $K_{i}$ becomes proportional to the applied stress. Considering the complete set of cracks contained in a rockfill specimen, the $K-\sigma$ relationships would plot as the fan shown in Fig. 13(c). In this figure, cracks have been ordered from 1 to $n$, where crack 1 has the lowest $a_{i} / D$ ratio and $n$ the largest one. Regions I, II and III have the same meaning as previously defined in Figs 9(a) and 12(a), and are also indicated in the $K-\sigma$ plot of Fig. 13(c). It follows from this figure that, in order to increase the stress intensity factor of crack $i$, initially having a value $K^{\mathrm{r}}-\Delta K$ under stress $\sigma_{0}$, to the target value $K^{\mathrm{r}}$, the stress increment should be

$$
\Delta \sigma=\frac{\Delta K}{K^{\mathrm{r}}-\Delta K} \sigma_{0}
$$

Replacing equation (17) in equation (18),

$$
\Delta \sigma \cong\left[\left(\frac{t}{t^{\mathrm{r}}}\right)^{1 / n}-1\right] \sigma_{0}
$$

which means that the total applied stress should be increased by a factor

$$
\frac{\sigma_{0}+\Delta \sigma}{\sigma_{0}} \cong\left(\frac{t}{t^{\mathrm{r}}}\right)^{1 / n}
$$

in order to get $\varepsilon=\varepsilon_{0}+\Delta \varepsilon$ at the reference time $\left(t^{\mathrm{r}}=\right.$ $1000 \mathrm{~min}$ )

Now the strain increment $\Delta \varepsilon$ developed during the time period $\Delta t$ can be computed, as induced by a stress increment $\Delta \sigma$ (Fig. 13(a)):

$$
\Delta \varepsilon=\int_{\sigma_{0}}^{\sigma_{0}+\Delta \sigma} \lambda\left(\sigma, \psi, t^{\mathrm{r}}\right) \frac{\mathrm{d} \sigma}{\sigma}
$$

Experimental values of the compressibility index in normal compression, shown in Fig. 5, suggest the existence of a two-stage behaviour. Following the nomenclature proposed by McDowell \& Bolton (1998), Oldecop \& Alonso (2001) called them clastic yielding (CY) and clastic hardening $(\mathrm{CH})$. During the first stage $(\mathrm{CY})$ the compressibility index follows a nearly linear relationship with the applied stress. This means that the stress-strain relationship in normal compression is nearly linear, as can be seen in Fig. 2(b). During the second stage $(\mathrm{CH})$ the compressibility index approaches a constant value. This implies a linear strain$\log$ (stress) normal compression line, as observed in Fig. 4. Oldecop \& Alonso (2003) proposed a constitutive model based on such two-stage behaviour of the compressibility index, and showed its ability to accurately reproduce the 
experiments. Assuming a linear increase of the compressibility index with the applied stress during CY, and a constant value during $\mathrm{CH}$, the integral in equation (21) is solved, and results in

\section{During CY:}

$$
\Delta \varepsilon \cong \lambda \frac{\Delta \sigma}{\sigma_{0}}
$$

During $\mathrm{CH}$ :

$$
\Delta \varepsilon \cong \lambda \ln \frac{\sigma_{0}+\Delta \sigma}{\sigma_{0}}
$$

Replacing equations (19) and (20) in equations (22) and (23) respectively, expressions for the development of strain in time under constant stress conditions are obtained.

\section{During CY:}

$$
\varepsilon \cong \lambda\left[\left(\frac{t}{t^{\mathrm{r}}}\right)^{1 / n}-1\right]+\varepsilon_{0}
$$

During $\mathrm{CH}$ :

$$
\varepsilon \cong \frac{\lambda}{n} \ln \frac{t}{t^{\mathrm{r}}}+\varepsilon_{0}
$$

Comparing equations (24) and (25), it can be seen that at $t=t^{\mathrm{r}}$ both lead to the same value of strain, $\varepsilon_{0}$. The slope of equation (24) (that is, the time-dependent compressibility index) is

\section{During CY:}

$$
\frac{\mathrm{d} \varepsilon}{\mathrm{d} t}=\frac{\lambda}{n t^{\mathrm{r}}}\left(\frac{t}{t^{\mathrm{r}}}\right)^{(1 / n)-1}=\frac{\lambda}{n t}\left(\frac{t}{t^{\mathrm{r}}}\right)^{1 / n}
$$

Hence at $t=t^{\mathrm{r}}$, equations (24) and (25) have the same slope, $\mathrm{d} \varepsilon / \mathrm{d} t=\lambda /(n t)$. As the Charles law parameter $n$ has relatively large values (20-200) (Atkinson, 1984; Swanson, 1984), equation (26) becomes

\section{During CY:}

$$
\frac{\mathrm{d} \varepsilon}{\mathrm{d} t} \cong \frac{\lambda}{n t}
$$

a value that also holds for the $\mathrm{CH}$ stage. Recalling the definition of the time-dependent compressibility index (equation (2)), it can be concluded that, in both the $\mathrm{CY}$ and $\mathrm{CH}$ stages,

$$
\frac{\lambda^{t}}{\lambda} \cong \frac{1}{n}
$$

It is shown therefore that the time-dependent compressibility, based on a logarithmic law, can be expressed in terms of the conventional compressibility coefficient and a parameter that describes the velocity of crack propagation associated with a stress corrosion effect. Equation (28) provides a justification for the relationship observed between $\lambda^{t}$ and $\lambda$. Lines for $\lambda^{t} /$ $\lambda=0.05(n=20)$ and $\lambda^{t} / \lambda=0.005(n=200)$, which reflect the possible range of values for $n$ from published experimental data for a wide range of rocks (Atkinson, 1984), have been plotted in Fig. 7. The resulting band includes all the experimental data reported in this work. The line $n=60$ defines reasonably well the relationship between $\lambda^{t}$ and $\lambda$ for low to medium suction values. For really dry states (suction $=255 \mathrm{MPa}$ ) water probably no longer has a significant effect, and subcritical crack propagation velocity decreases substantially, as shown by the large value of the $n$ parameter of the Charles law, which fits the recorded compressibility indices for the tested shale. In fact, subcritical crack growth curves in zone 3 are much steeper than in zone 1 , and have $n$ values typically larger than 150 (Wiederhorn, 1982; Atkinson, 1984).

\section{CONCLUSIONS}

Creep behaviour of rockfill, under various moisture conditions imposed in suction-controlled oedometer tests on compacted gravel of a quartzitic slate, was analysed on the basis of the strain records obtained for every loading step. The experimental data support the existence of a unique relationship between strain, stress, total suction and time for longterm creep behaviour. Such a relationship is best approached by a linear strain- $\log ($ time $)$ function, a feature that is also supported by settlement records of rockfill dams. It was also shown that the coefficient of creep deformation $\left(\lambda^{t}\right)$ and the compressibility coefficient $(\lambda)$ follow similar relationships with applied stress and suction. In fact, the ratio $\lambda^{t} / \lambda$ tends to be a constant close to 0.02 for most of the tests performed, except for very dry states, characterised by a lower ratio $(0 \cdot 005)$.

The delayed deformation of rockfill is explained by the progressive breakage of stressed particles. The conceptual model proposed here relies on the subcritical propagation of cracks existing in loaded rock particles. The velocity of crack propagation is a function of the local stress intensity factor and the prevailing relative humidity. A simple relationship for this function (Charles law) has been adopted here to gain a deeper insight into the deformation mechanisms of rockfill and to provide a physical explanation for the experimental observations mentioned before.

Adopting simplified geometry and loading conditions for the rock particles (cracked discs under a diametrically opposed concentrated loading), it was found that, in a first stage, the crack propagates slowly. At some critical time the velocity of propagation increases rapidly, and a sudden breakage takes place. The time to breakage may change by many orders of magnitude for relatively small changes in the initial crack length. This result provides an explanation for the apparently never-ending process of settlement accumulation observed in rockfill structures.

Results given by the crack propagation in discs have been interpreted from a different perspective when initial sizes of propagating cracks are plotted against the confining stress and the expected survival time. For a given time interval of interest in practice the size of active cracks could be found. Active cracks increase in size as the confining stress decreases, but the range of possible values decreases rapidly as the particle size is approached by the initial crack length. This phenomenon explains why delayed effects disappear for low confining stresses, which is an observation made in large-scale experiments.

An additional consequence of the model is that a one-toone relationship can be established between the initial stress intensity factor and the time to particle breakage. As stress intensity factors and macroscopic stresses are approximately related in a linear manner, an expression for the development of deformations in time could eventually be found between strain, time, and the compressibility coefficient. The model predicts a linear increase of strain with the logarithm of time, as observed in the reported tests. It was found that the common coefficient of creep could be expressed in a very simple manner in terms of the compressibility coefficient and a parameter describing the rate of crack propagation (the parameter $n$ of the Charles law for stress corrosion). This relationship is supported by experimental observations, and provides a physical explanation for the values adopted in practice by the ratio $\lambda^{t} / \lambda$.

The clue to the theoretical work presented here is recogni- 
tion of the fact that subcritical propagation of cracks in rocks is a two-stage process. This singular feature makes it possible to establish a one-to-one relationship between the initial stress intensity factor and the time to particle breakage. Moreover, because of the same feature, this relationship holds no matter what the actual dimensions of the particle or the position of the crack within the particle. This means that the proposed model would apply not only for particles undergoing splitting but also for other deformation mechanisms involving the growth of cracks. In particular, localised crushing in the vicinity of interparticle contacts has long been recognised as an important source of deformation in rockfill (Kjaernsli \& Sande, 1963; Sowers et al., 1965; Clements, 1981). Although the mechanism of contact crushing is complex, and not yet fully understood, some type of cracking is involved at contacts. Hence it seems reasonable to think that the conclusions of this work may also apply to granular materials deforming by contact crushing.

\section{ACKNOWLEDGEMENTS}

Some of the dam monitoring data presented in this work were kindly provided by Hidroeléctrica Chocón S.A. and Hidroeléctrica Alicurá S.A. The authors gratefully acknowledge the financial support given to the first author by the Ministerio de Educación y Ciencia from Spain and the Universidad Nacional de San Juan (Argentina) during the research work reported in this paper.

\section{APPENDIX. DERIVATION OF EQUATION (6)}

Inverting equation (5) and integrating, a relationship between time and crack length is obtained:

$$
\begin{aligned}
& \mathrm{d} t=\frac{1}{A_{i}} a_{i}^{-n / 2} \mathrm{~d} a_{i} \\
& t \cong-\frac{1}{A_{i}} \frac{1}{n / 2-1} a_{i}^{-(n / 2-1)}+C
\end{aligned}
$$

where $C$ is the integration constant. At the instant $t=0$, when the new load conditions (stress and suction) are just applied, the considered crack has a certain initial length $a_{0 i}$, and hence constant $C$ becomes

$$
C=\frac{1}{A_{i}} \frac{2}{n-2} a_{0 i}^{-((n / 2)-1)}
$$

Replacing equation (31) in equation (30),

$$
t=\frac{1}{A_{i}} \frac{2}{n-2}\left(a_{0 i}^{-((n / 2)-1)}-a_{i}^{-((n / 2)-1)}\right)
$$

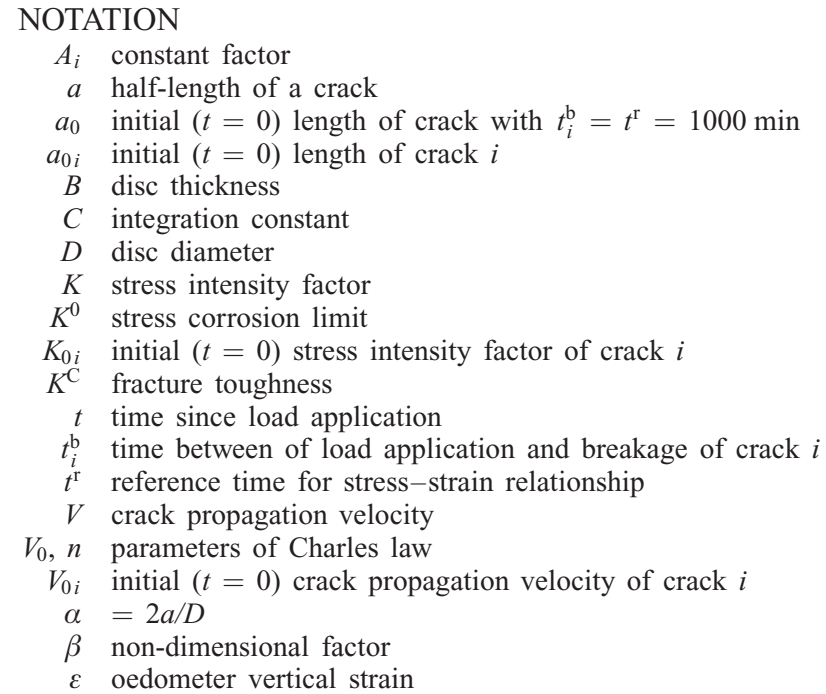

$\varepsilon_{0} \quad$ strain attained after $t^{\mathrm{r}}$ has elapsed since instant of application of stress $\sigma_{0}$

$\eta$ correction factor for time to breakage

$\lambda$ compressibility index

$\lambda^{t}$ time-dependent compressibility index

$\sigma$ oedometer vertical stress or macroscopic stress

$\sigma_{i}^{*} \quad$ stress that would act across plane of crack $i$ if particle was non-cracked

$\chi_{i}$ proportionality factor between $\sigma_{i}^{*}$ and $\sigma$

$\psi$ total suction

\section{REFERENCES}

Athanasiu, C., Simonsen, A. S., Soereide, O. K. \& Tistel, J. (2005). Elastic and creep settlements of rock fills. Proc. 16th Int. Conf. Soil Mech. Geotech. Engng, Osaka, 1837-1843.

Atkinson, B. K. (1984). Subcritical crack growth in geological materials. J. Geophys. Res. 89, No. B6, 4077-4114.

Atkinson, B. K. \& Meredith, P. G. (1987). The theory of subcritical crack growth with applications to minerals and rocks. In Fracture mechanics of rock (ed. B. K. Atkinson), pp. 111-166. London: Academic Press.

Broek, D. (1986). Elementary engineering fracture mechanics. Dordrecht: Martinus Nijhoff.

Cetin, H., Laman, M. \& Ertunç, A. (2000). Settlement and slaking problems in the world's fourth largest rock-fill dam, the Ataturk Dam in Turkey. Engng Geol. 56, No. 3, 225-242.

Clements, R. P. (1981). The deformation of rockfill: inter-particle behaviour, bulk properties and behaviour in dams. $\mathrm{PhD}$ thesis, Faculty of Engineering, King's College, University of London.

Charles, J. A. (1989). Geotechnical properties of coarse grained soils. Proc. of $12^{\text {th }}$ Int. Conf. Soil Mech. Found. Engng, Rio de Janeiro, General Report, Discussion Session 8, 2495-2519.

Charles, J. A. (1991). Laboratory compression tests and the deformation of rockfill structures. In Advances in Rockfill Structures. NATO ASI Series E, Vol. 200, pp. 73-95.

Charles, R. J. (1958). Static fatigue of glass. J. Appl. Phys. 29, No. 11, 1549-1560.

Coussy, O. (1995). Mechanics of porous continua. Chichester: John Wiley \& Sons.

Cundall, P. A. \& Strack, O. D. L. (1979). A discrete numerical model for granular assemblies. Géotechnique 29, No. 1, 47-65.

Freiman, S. W. (1984). Effects of chemical environments on slow crack growth in glasses and ceramics. J. Geophys. Res. 89, No. B6, 4072-4076.

Fumagalli, E. (1969). Tests on cohesionless materials for rockfill dams. J. Soil Mech. Found. Engng ASCE 95, No. SM1, 313330.

ISRM (1978). Suggested methods for determining tensile strength of rock materials. Int. J. Rock Mech. Min. Sci. Geomech. Abstr. 15, No. 3, 99-103.

Justo, J. L. \& Durand, P. (2000). Settlement-time behaviour of granular embankments. Int. J. Numer. Anal. Methods Geomech. 24, No. 3, 281-303.

Kjaernsli, B. \& Sande, A. (1963). Compressibility of some coarsegrained materials. Proc. Eur. Conf. Soil Mech. Found. Engng, Wiesbaden, 1, 245-251.

Marachi, N. D., Chan, C. K., Seed, H. B. \& Duncan, J. M. (1969). Strength and deformation characteristics of rockfill materials, Report No. TE-69-5. Department of Civil Engineering, University of California.

Marsal, R. J. (1973). Mechanical properties of rockfill. In Embankment dam engineering. Casagrande Volume I (eds R. C. Hirschfeld and S. J. Poulos). New York: John Wiley \& Sons, 110-200.

Marsal, R. J., Arellano, L. R., Guzmán, M. A. \& Adame, H. (1976). El Infiernillo. In Behavior of dams built in Mexico. UNAM, México: Instituto de Ingeniería, 239-312.

McDowell, G. R. \& Bolton M. D. (1998). On the micromechanics of crushable aggregates. Géotechnique 48, No. 5, 667-679.

Mesri, G. \& Castro, A. (1987). $\mathrm{C}_{\alpha} / \mathrm{C}_{\mathrm{c}}$ concept and $K_{0}$ during secondary compression. J. Geotech. Engng, ASCE 113, No. 3, 230-247.

Mesri, G., Feng, T. W. \& Benak, J. M. (1990). Postdensification penetration resistance of clean sands. J. Geotech. Engng ASCE 116, No. 7, 1095-1115. 
Nakata, Y., Kato, Y., Hyodo, M., Hyde, A. \& Murata, H. (2001). One-dimensional compression behaviour of uniformly graded sand related to single particle crushing strength. Soils Found. 41, No. 2, 39-51.

Naylor, D. J., Maranha, J. R., Maranha das Neves, E. \& Veiga Pinto, A. A (1997). A back-analysis of Beliche Dam. Géotechnique 47, No. 2, 221-233.

Nobari, E. S. \& Duncan, J. M. (1972). Effect of reservoir filling on stresses and movements in earth and rockfill dams, Report No. TE-72-1. Department of Civil Engineering, University of California.

Oldecop, L. A. \& Alonso, E. E. (2001). A model for rockfill compressibility. Géotechnique 51, No. 2, 127-139.

Oldecop, L. A. \& Alonso, E. E. (2003). Suction effects on rockfill compressibility. Géotechnique 53, No. 2, 289-292.

Sherard, J. L. \& Cooke, J. B. (1987). Concrete-face rockfill dam: I. Assessment. J. Geotech. Engng ASCE 113, No. 10, 10961112.

Soriano, A. \& Sánchez, F. J. (1999) Settlements of railroad high embankments. Proc. 12th Eur. Conf. Soil Mech. Geotech. Engng Amsterdam, 1885-1890.

Soriano, A., Sánchez, F. \& Macías, J. M. (1992). Presa Rivera de la
Gata: primer llenado. Revista de Obras Públicas 139, No. 3309 , $169-184$.

Sowers, G. F., Williams, R. C. \& Wallace, T. S. (1965). Compressibility of broken rock and settlement of rockfills. Proc. 6th Int. Conf. Soil Mech. Found. Engng, Montreal 2, 561-565.

Swanson, P. L. (1984). Subcritical crack growth and other time- and environment- dependent behaviour in crustal rocks. J. Geophys. Res. 89, No. B6, 4137-4152.

Tada, H., Paris, P. C. \& Irwin, G. R. (1985). The stress analysis of cracks handbook, 2nd edn. St Louis, MO: Paris Productions.

Veiga Pinto, A. A. (1983). Previsão do comportamento estrutural de barragens de enrocamento. $\mathrm{PhD}$ thesis, Laboratório Nacional de Engenharia Civil, Lisbon.

Wiederhorn, S. M., Fuller, E. R. \& Thomson, R. (1980). Micromechanisms of crack growth in ceramics and glasses in corrosive environments. Met. Sci. 14, Aug.-Sept., 450-458.

Wiederhorn, S. M., Freiman, S. W., Fuller, E. R. \& Simmons, C. J. (1982). Effects of water and other dielectrics on crack growth. J. Mater. Sci. 17, No. 12, 3460-3478.

Yamamuro J. A. \& Lade, P. V. (1996). Drained sand behavior in axisymmetric tests at high pressures. J. Geotech. Engng ASCE 122, No. 2, 109-119. 